\title{
Perangkat Media Terapi Bagi Anak Penderita Fobia Jarum Suntik (Trypanophobia) Menggunakan Teknologi Augmented Reality
}

\author{
Evans Fuad, Rahmad Gunawan, Januar Al Amien, Ulva Elviani \\ Teknik Informatika, Universitas Muhammadiyah Riau, Indonesia \\ E-mail: evansfuad@umri.ac.id, rahmadgunawan@umri.ac.id,januar.alamien@umri.ac.id, \\ ulvaelviani@student.umri.ac.id
}

\begin{abstract}
Abstrak
Fobia adalah suatu keadaan dimana seseorang mengalami rasa takut yang berlebihan terhadap suatu objek tertentu sehingga menimbulkan ketakutan tidak rasional yang dapat mengancam keselamatan diri. Berdasarkan data yang di peroleh dari Dinas Kesehatan Kabupaten Siak dalam melakukan imunisasi di SDN 003 Benteng Hilir, dari 25 orang siswa kelas 1 (satu) SD yang dilakukan imunisasi, 18 orang diantaranya menderita fobia terhadap jarum suntik (Trypanophobia). Oleh karena itu, untuk mengatasi hal tersebut maka perlu di bangun sebuah aplikasi sebagai media terapi fobia jarum suntik. Aplikasi yang akan dibangun dalam penelitian ini menerapkan teknologi augmented reality sebagai media terapi berbasis mobile. Pendekatan yang digunakan yaitu desentisiasi sistematis menuju ke tahap flooding, dimana tim medis akan membimbing pasien dalam melakukan terapi yang diawali dengan memberikan informasi seputar fobia melalui aplikasi kemudian mengarahkan mobile ke gelang marker yang sudah terpasang di tangan pasien agar pasien dapat berinteraksi dengan objek jarum suntik secara langsung. Berdasarkan hasil pengujian yang dilakukan secara blackbox, dapat disimpulkan bahwa aplikasi trypanophobia dapat memberikan informasi yang cukup jelas kepada pasien serta dapat membantu tim medis dengan cepat mengendalikan rasa takut pasien sebelum melakukan injeksi.
\end{abstract}

Kata Kunci: Augmented Reality, Desentisiasi, Flooding, Augmented Reality, trypanophobia

\section{Abstract}

Phobia is a condition in which a person experiences excessive fear of a particular object, giving rise to irrational fears that can threaten personal safety. Based on the data obtained from the Siak District Health Office in conducting immunizations at SDN 003 Benteng Hilir, out of 25 class 1 (one) elementary school students who were immunized, 18 of them suffered from needle phobia (Trypanophobia). Therefore, to overcome this problem, it is necessary to build an application as a medium for the therapy of needle phobia. The application that will be built in this study applies augmented reality technology as a mobilebased therapeutic medium. The approach used is systematic desentisiasi to the stage of flooding, where the medical team will guide patients in conducting therapy which begins with providing information about phobias through the application then directs the mobile to the marker bracelet that has been installed in the patient's hand so that the patient can interact with the syringe object directly. Based on the results of tests conducted in blackbox, it can be concluded that the application of trypanophobia can provide sufficiently clear information to patients and can help the medical team quickly control the patient's fear before injection

Keywords: Augmented Reality, Desentisiasi, Flooding, Augmented Reality, trypanophobia

\section{PENDAHULUAN}

Dalam beberapa tahun terakhir Augmented Reality (AR) menjadi bidang yang penting dalam penelitian. AR merupakan penggabungan benda-benda yang ada di dunia maya (virtual) ke dalam dunia nyata dalam bentuk dua dimensi maupun tiga dimensi yang dapat disentuh, maupun dilihat, dan juga dapat didengar. AR memberikan peluang besar dalam ilmu sains dan teknik karena disiplin ilmu ini menekankan pada pelatihan praktis secara langsung (real time) [1]. Dengan teknik AR, seseorang dapat mendapatkan sensasi penjelajahan dan pembelajaran dengan cara yang berbeda dan unik karena dia telibat langsung didalamnya.

Fobia merupakan suatu keadaan dimana seseorang merasa ketakutan yang berlebihan akan suatu hal tertentu, baik itu berupa objek nyata, maupun perasaan-perasaan yang di timbulkan dengan sendirinya. Pada dasarnya fobia berasal dari rasa takut yang tidak rasional atas sesuatu yang spesifik atau gangguan kecemasan yang di picu oleh stimulus yang tidak benar-benar menakutkan serta mengancam keselamatan diri. Trypanophobia atau yang dapat di sebut dengan fobia terhadap jarum suntik adalah salah satu dari jenis fobia specific phobic, yaitu salah satu kategori fobia dalam DSM-IV (Diagnostic and Statistical Manual for Mental Disorder IV). Dalam Azmarina (2015) fobia spesifik ini terbagi lagi menjadi beberapa spesifikasi salah satu nya yakni Blood Injury Injection Phobia (BII), dimana fobia jarum suntik merupakan bagian dari BII [2].

Terapi yang dapat dinyatakan efektif untuk menanggani masalah ini adalah dengan menggunakan terapi Audio Hipnoterapi atau CD Hipnoterapi. Sedangkan penanganan lainnya yaitu menggunakan Desentisiasi. Audio Hipnoterapi adalah terapi berupa sugesti dan kebanyakan berada pada alam bawah sadar pasien, sedangkan Desentisiasi merupakan terapi secara bertahap, dimana pasien di hadapkan pada objek yang mirip dengan jarum suntik asli, sampai mirip ataupun dengan jarak yang jauh atau jarak yang dekat. Tahapan terakhir dari terapi ini yaitu terapi flooding dimana pasien akan di hadapkan langsung dengan jarum suntik secara langsung [3].

Masalah yang muncul dari terapi tersebut yaitu ketika pasien sudah melewati tahapan-tahapan terapi, namun pada saat masuk ke dalam tahapan terapi flooding pasien masih memiliki rasa takut yang cukup tinggi. Hal ini di sebabkan karena tidak semua orang dapat di hipnoterapi di karenakan oleh beberapa faktor salah satu nya yaitu 
tidak fokus ketika dilakukan sugesti, sama hal nya dengan Desentisiasi yang menerapkan terapi dengan menggunakan gambar, video, objek dan benda yang tidak terlalu mirip yang asli. Selain itu, pasien masih kurang mengetahui informasi mengenai terapi untuk menangani fobia nya sendiri di samping menjalani terapi di rumah sakit agar penyembuhan dapat berjalan efektif.

Penelitian ini bertujuan untuk membuat suatu teknik terapi terhadap penderita Trypanophobia dengan menggunakan teknologi Augmented Reality sehingga di harapkan mampu membantu bidang medis dalam melakukan injeksi menggunakan jarum suntik kepada pasien.

\section{TEORITIS}

\subsection{Fobia Pada Jarum Suntik}

Fobia merupakan rasa ketakutan yang berlebihan pada sesuatu hal atau fenomena. Fobia bisa dapat mengganggu kehidupan orang yang mengidapnya. Bagi sebagian orang, perasaan takut seorang pengidap fobia sulit dimengerti. Perilaku dari penderita fobia terhadap jarum suntik, ditunjukkan dengan adanya ketakutan dan usaha menghindari jarum suntik pada saat pengambilan darah. Bahkan kemungkinan penderita dapat jatuh sakit akibat tidak kuat melihat jarum suntik [2].

Beberapa bentuk emosi yang dirasakan dari fobia jarum suntik yang dikutip dari penelitiannya sebagai berikut [2]:

1. Saya takut disuntik

2. Saya menghindar untuk tidak disuntik

3. Saya khawatir apabila harus disuntik

4. Saya merasa muak ketika disuntik

5. Saya takut melihat orang lain disuntik

6. Saya merasa gelisah apabila melihat orang lain disuntik.

Sejarah teknik desensitisasi sitematis, Nietzel dan Berstein dalam Corel (2007) mengemukakan tentang latar belakang teknik ini antara lain tokoh Watson dan Rayner melihat bahwa rasa takut dipelajari lewat conditioning, demikian juga sebaliknya rasa takut dapat dihilangkan lewat counter conditioning [4].

Desensitisasi sistematis adalah salah satu teknik yang paling luas digunakan dalam terapi tingkah laku. Desensitisasi sistematis digunakan untuk menghapus tingkah

\subsection{Augmented Reality}

Augmented Reality (AR) adalah sebuah teknologi yang menggabungkan benda maya baik dua atau tiga dimensi ke dalam sebuah lingkungan nyata dan memproyeksikannya ke dalam satuan waktu yang nyata [5]. Benda-benda maya yang diproyeksikan tersebut menampilkan informasi yang tidak dapat diterima oleh pengguna dengan inderanya sendiri. Hal ini membuat augmented reality sesuai sebagai alat untuk membantu persepsi dan interaksi penggunanya dengan dunia nyata. Informasi yang ditampilkan oleh benda maya membantu pengguna melaksanakan kegiatan-kegiatan dalam dunia nyata. Terdapat 2 jenis metode pencitraan dalam augmented reality [6].

1. $\quad$ Marker Based Tracking

Salah satu metode yang sudah cukup lama dikenal dalam teknologi augmented reality adalah Marker Based Tracking. Sistem dalam AR ini membutuhkan penanda (marker) berupa gambar yang dapat dianalisis untuk membentuk reality. Penanda gambar tersebutlah yang disebut dengan marker. Marker-Based AR memiliki ciri khas yakni menggunakan fitur kamera pada device untuk menganalisa marker yang tertangkap untuk menampilkan obyek virtual seperti video.

2. Markerless Augmented Reality

Salah satu metode augmented reality yang saat ini sedang berkembang adalah metode Markerless Augmented Reality, dengan metode ini pengguna tidak perlu lagi menggunakan sebuah marker untuk menampilkan elemen-elemen digital.

Dalam penerapannya teknologi augmented reality memiliki beberapa komponen yang harus ada untuk mendukung kinerja dari proses pengolahan citra digital. Adapun komponen-komponen tersebut adalah sebagai berikut [7]
a. Scene generator
b. Tracking system
c. Display
d. AR Devices.

\subsection{NFT (NATURAL FEATURE TRACKING)}

NFT (NATURAL FEATURE TRACKING) Yaitu proses mendeteksi keberadaan penanda atau marker dengan melihat semua feature-nya. Dimana setelah marker terdeteksi akan mengalami beberapa poses pada marker. Tujuannya adalah agar pendeteksian lebih mudah. Gambar atau marker yang akan digunakan sebagai marker 
perlu konversi terlebih dahulu menjadi file berekstensi *.xml sebelum dapat digunakan dalam kode, yaitu dengan mengunakan fasilitas yang terdapat di situs www.developer.vuforia.com dengan memilih target manager. Marker yang dipilih oleh pengguna akan dilakukan pengecekan feature-nya. Sebuah fitur adalah tajam, berduri, detil dipahat dalam gambar, seperti yang hadir dalam benda bertekstur. Gambar analyzer merupakan fitur seperti salib kuning kecil untuk mengenali jumlah rincian feature dalam gambar, dan melakukan verifikasi bahwa rincian membuat pola yang tidak berulang [8].

1. Sift (Scale Invariant Feature Transform)

Scale Invariant Feature Transform merupakan metode yang mengambil titik-titik fitur yang ada pada suatu citra, untuk membantu memastikan dalam pencocokan titik fitur suatu obyek pada sudut pandang yang berbeda. Pendekatan ini mengubah sebuah gambar menjadi sebuah koleksi besar dari vektor fitur lokal, yang masing-masing adalah invarian terhadap translasi, scaling, dan rotasi citra, dan sebagian invarian perubahan pencahayaan dan proyeksi 3D [9].

2. Ferns Tracking By Classification

Metode Ferns merupakan sebuah metode yang memanfaatkan kesesuaian titik kunci (keypoint) sebuah citra. Metode ini digunakan untuk mendeteksi objek yang berupa bidang datar. Pada metode Ferns, mengidentifikasi petak tekstur yang dikelilingi oleh titik kunci pada citra diperoleh dari beragam bentuk dan kondisi pencahayaan. Hasil yang diperoleh dapat digunakan untuk mencatat perbedaan sudut pandang dari keadaan yang sama, mengekstraksi informasi objek 3D, atau mengikuti objek dalam video [10]. Ferns menggunakan klasifikasi fitur yang cepat, tetapi membutuhkan kapasitas memori yang besar.

\section{ANALISA DAN PEMBAHASAN}

Analisis marker merupakan tahapan dalam menganalisis bentuk dan isi dari penanda yang akan digunakan. Marker adalah sebuah perangkat keras lainnya yang menjadi salah satu bagian dari Augmented Reality (AR) atau biasa di sebut dengan penanda. Adapun alur untuk pendeteksian marker yang digunakan pada aplikasi di Unity 3D dapat diilihat pada gambar 2 berikut:

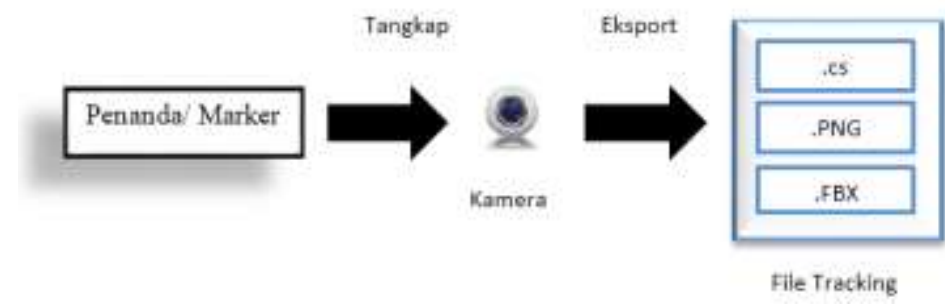

Gambar 1. Alur Pendeteksian Marker

Penjelasan dari alur pendeteksian marker dapat dijabarkan sebagai berikut:

1. Penanda merupakan marker yang ditempelkan di tangan dan akan di proses ke dalam database melalui deteksi kamera, kemudian di eksport menjadi file tracking.

2. Kamera yang digunakan untuk pendeteksian marker dapat menggunakan kamera smartphone/laptop atau pun webcame dan kamera eksternal.

3. File tracking adalah hasil dari deteksi penanda yang berisi marker ke dalam file berupa .PNG dan .FBX. .PNG berupa gambar yang dijadikan marker, sedangkan .FBX file berupa objek.

Use case diagram merupakan gambaran graphical dari aktor, dimana pada use case diagram akan menerangkan manajemen sistem secara keseluruhan.

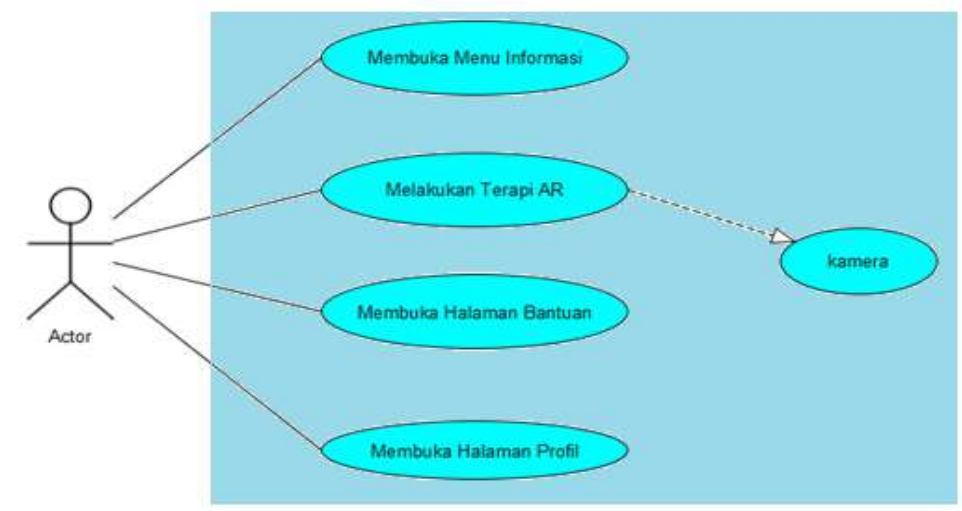

Gambar 2. Usecase Diagram

Definisi aktor adalah definisi yang menerangkan tentang pengguna (user) di dalma sebuah aplikasi. Definisi aktor dapat dilihat pada tabel 2 berikut: 
Tabel 1. Definisi Aktor

\begin{tabular}{lll}
\hline No & Aktor & Deskripsi \\
\hline 1. & User & Orang yang menggunakan aplikasi \\
\hline
\end{tabular}

Use case adalah definisi yang menerangkan tentang fungi-fungsi dari sistem aplikasi. Definisi use case dapat dilihat pada tabel 3 berikut:

Tabel 2. Definisi Use Case Diagram

\begin{tabular}{|c|c|c|}
\hline No & Use case & Deskripsi \\
\hline 1. & $\begin{array}{l}\text { Membuka menu } \\
\text { informasi }\end{array}$ & $\begin{array}{l}\text { Use Case ini berfungsi untuk membuka halaman informasi yang berisi materi- } \\
\text { materi serta informasi-informasi seputar fobia. Pada menu ini terdapat } 3 \text { menu } \\
\text { pilihan yaitu informasi untuk jenis-jenis fobia, tingkatan fobia dan penanggan fobia. } \\
\text { Adapun materi pada menu informasi dapat dilihat pada tabel } 4\end{array}$ \\
\hline 2. & $\begin{array}{l}\text { Memulai Terapi } \\
\text { AR }\end{array}$ & $\begin{array}{l}\text { Use case ini berfungsi untuk membuka halaman AR dan mengaktifkan kamera. } \\
\text { Kamera akan mendeteksi marker dan menampilkan ilustrasi objek 3D untuk proses } \\
\text { terapi. }\end{array}$ \\
\hline 3. & $\begin{array}{l}\text { Membuka } \\
\text { halaman bantuan }\end{array}$ & $\begin{array}{l}\text { Use case ini berguna untuk memberikan dan menampilkan informasi tentang tata } \\
\text { cara penggunaan aplikasi }\end{array}$ \\
\hline 4. & $\begin{array}{l}\text { Membuka } \\
\text { halaman profil }\end{array}$ & Use case ini berfungsi untuk menampilkan informasi tentang pengembang aplikasi \\
\hline
\end{tabular}

Tabel 3. Informasi Menu Pilih Materi

\begin{tabular}{ll}
\hline No & Menu Materi \\
\hline 1. & Jenis-jenis Fobia
\end{tabular}

\section{Isi Materi}

a. Fobia Spesifik

- Fobia hewan (contoh: fobia tikus, anjing, atau hewan lainnya)

- Fobia lingkungan alam (contoh : fobia ketinggian, kilat, air)

- Fobia luka darah atau suntikan

b. Fobia situasional

- Conttoh: fobia ketika berada di dalam pesawat, lift, atau tempat tertutup

c. Fobia spesifik lain

- Contoh: fobia terhadap kostum tertentu pada anak-anak

d. Fobia sosial

- Fobia yang berhubungan dengan kehadiran orang lain, dan individu cenderung menghindar)

2. Tingkatan fobia

a. Awal (ketakutan yang wajar)

- Gejala: adanya rasa kecemasan/ketakutan di pikiran, takut untuk berinteraksi, kewaspadaan yang mengganggu, reaksi menghindar dari jarak yang tidak terlalu jauh $(<3 \mathrm{~m})$

b. Menengah (ketakutan yang menengah)

- Gejala: reaksi menghindar dari jarak yang jauh (> $3 \mathrm{~m}$ ), peningkatan rasa cemas, kewaspadaan berlebih, munculnya keringat berlebih.

c. Akut (ketakutan yang berlebihan)

- Gejala: jantung berdebar, rasa cemas bahkan untuk objek yang mirip, reaksi menghindar yang sangat jauh, adanya reaksi tubuh yang terjadi, otot mulai menengang, mulai adanya gejala sakit kepala, muncul kerinat dingin yang banyak.

d. Kronis (ketakutan yang luar biasa)

- Gejala: rasa cemas bahkan untuk objek yang tidak terlalu mirip, mual/muntah ketika melihat objek, sesak nafas yang parah, melakukan berbagai cara untuk menghindar objek, kerinat dingin yang dikeluarkan sangat banyak, tubuh gemetar terus-menerus.

3. Penangganan fobia

a. Pendekatan psikoanalisis

- Penangganan yang bertujuan untuk mengungkapkan konflik-konflik yang mendasari munculnya ketakutan yang ekstrrem dan reaksi menghindar.

b. Pendekatan behavioral

- Pendekatan yang menggunakan desentisiasi sistematis dalam penangganannnya

c. Pendekatan kognitif

- Pendekatan dengan pendekatan biologis, yaitu dengan pemberian obatobatan sedative, tranquilizer, atau anxiolyticss yang dapat mengurangi kecemasan dan ketakutan. 
Desain user interface yang akan di buat menggunakan storyboard yang akan di paparkan pada tabel 5 sebagai berikut:

Tabel 5. Desain User Interface

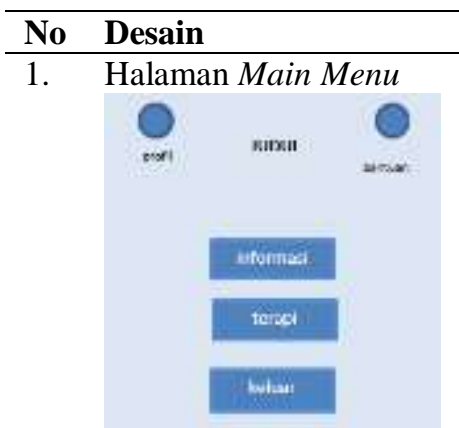

2. Halaman Menu Informasi

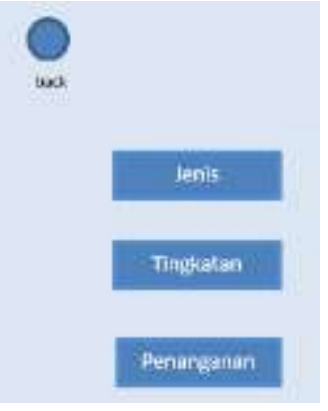

3. Halaman Menu Terapi

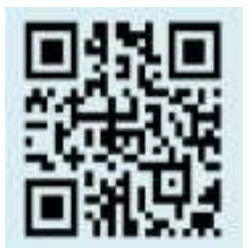

4. Halaman Bantuan Juout

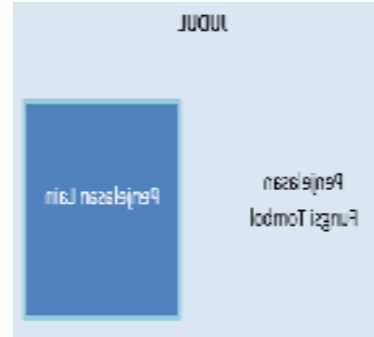

Deskripsi

Pada halaman utama (Main Menu) terdapat judul dan 5 menu utama, yaitu menu informasi, menu terapi yang menpakan halaman AR, meu keluar, menu bantuan

Pada halaman menu informasi terdapat 3 menu utama, yaitu menu jenis untuk menampilkan informasi seputar jenis fobia, menu tingkatan untuk menampilkan informasi seputar tingkatan fobia, dan menu penanganan untuk menampilkan informasi seputar penangganan fobia.

Halaman $A R$ akan mengaktifkan kamera $A R$. Jika kamera di arahkan di atas marker maka sistem akan menampilkan obyek yang sudah disesuaikan (ilustrasi animasi 3D).

Halaman bantuan akan menampilkan penjelasan tentang fungsi tombol pada main mеnu dan penjelasan lain terkait cara penggunaan aplikasi Trypanophobia.

Informasi yang akan ditampilkan pada menu pilih materi terdiri dari jenis-jenis fobia.

Tabel 6. Informasi

\begin{tabular}{|c|c|c|}
\hline No & Menu Materi & Isi Materi \\
\hline 1. & Jenis-jenis Fobia & $\begin{array}{l}\text { 1. Fobia Spesifik } \\
\text { - Fobia hewan (contoh : fobia tikus, anjing, atau hewan lainnya) } \\
\text { - Fobia lingkungan alam (contoh: fobia ketinggian, kilat, air) } \\
\text { - Fobia luka darah atau suntikan } \\
\text { 2. Fobia situasional } \\
\text { - Conttoh: fobia ketika berada di dalam pesawat, lift, atau tempat tertutup } \\
\text { 3. Fobia spesifik lain } \\
\text { - Contoh: fobia terhadap kostum tertentu pada anak-anak } \\
\text { 4. Fobia sosial } \\
\text { - Fobia yang berhubungan dengan kehadiran orang lain, dan individu cenderung } \\
\text { menghindar) }\end{array}$ \\
\hline
\end{tabular}


1. Awal (ketakutan yang wajar)

- Gejala: adanya rasa kecemasan/ketakutan di pikiran, takut untuk berinteraksi, kewaspadaan yang mengganggu, reaksi menghindar dari jarak yang tidak terlalu jauh $(<3 \mathrm{~m})$

2. Menengah (ketakutan yang menengah)

- Gejala: reaksi menghindar dari jarak yang jauh (> $3 \mathrm{~m}$ ), peningkatan rasa cemas, kewaspadaan berlebih, munculnya keringat berlebih.

3. Akut (ketakutan yang berlebihan)

- Gejala: jantung berdebar, rasa cemas bahkan untuk objek yang mirip, reaksi menghindar yang sangat jauh, adanya reaksi tubuh yang terjadi, otot mulai menengang, mulai adanya gejala sakit kepala, muncul kerinat dingin yang banyak.

4. Kronis (ketakutan yang luar biasa)

- Gejala: rasa cemas bahkan untuk objek yang tidak terlalu mirip, mual/muntah ketika melihat objek, sesak nafas yang parah, melakukan berbagai cara untuk menghindar objek, kerinat dingin yang dikeluarkan sangat banyak, tubuh gemetar terus-menerus.

\section{KESIMPULAN}

Berdasarkan hasil pembahasan yang telah di paparkan, maka di dapat di tarik beberapa kesimpulan sebagai berikut:

1. Aplikasi Trypanophobia mampu memberikan informasi yang cukup bagi penderita fobia jarum suntik dikarenakan informasi di sajikan secara ringkas dan mudah di pahami melalui visual.

2. Aplikasi ini dapat dijadikan sarana latihan bagi penderita fobia jarum suntik untuk mengendalikan rasa takutnya sebelum melakukan injeksi.

3. Dengan penerapan augmented reality sebagai terapi fobia jarum suntik dapat membantu tim medis secara cepat dalam memberikan sugesti dan mengubah mindset pasien terhadap jarum suntik ke arah yang lebih positif.

\section{REFERENCES}

[1] Andujar, J.M, Mejias, A, Marquez, M.A., 2011, Augmented Reality for the Improvement of Remote Laboratories: An Augmented Remote Laboratory, Education, IEEE Transactions on , vol.54, no.3, pp.492,500

[2] Ambarita, Togi Fitri Andriani, 2015, Problema Fobia Jarum Suntik dan Penanganannya Dengan Pendekatan Terapi Behaviour, Jurnal Psikologi. Universitas HKBP NOMMENSEN: Medan

[3] Budiyanto, 2015, Pemanfaatan Augmented Reality Sebagai Media Terapi Penderita Fobia Terhadap Hewan, Jurnal Teknik Informatika. Universitas Komputer Indonesia: Bandung.

[4] Corey, Gerald. 2007. Teori dan Praktek Konseling dan Psikoterapi. Bandung: Refika Aditama

[5] Grubert, Jens, Dr. Grasset Raphael. (2013). Augmented Reality for Android Application Development. PACKT Publishing, BirminghamMumbai.

[6] Lyu, Michael R. (2012). Digital Interactive Game Interface Table Apps for Ipad. Jurnal Penelitian. The Chinese University of Hongkong.

[7] Sylva, R., Oliveira, J. C., \& Giraldi, G. A. (2003). Introduction in Augmented Reality. Jurnal Penelitian. LNCC. Brazil.

[8] Rentor, Mario Fernando. (2013). Rancang Bangun Perangkat Lunak Pengenalan Motif Batik Berbasis Augmented Reality. Universitas Atma Jaya. Yogyakarta.

[9] David G. Lowe. (2004). Object Recognition from Local ScaleInvariant Features, Computer Science Department, University of British Columbia.

[10] Bimantoro, S., Kuswardayan, I. \& Sarwosi (n.d) Pembuatan alat kemudi dengan menggunakan Open Computer Vision untuk spceship pada game orbiter space flight simulator. Institut Sepuluh Nopember Kmpus ITS Sukalio. Surabaya 